\title{
DOES SHORT-TERM AIR POLLUTION EXPOSURE HAVE EFFECTS ON BLOOD PRESSURE AND HEART RATE IN HEALTHY WOMEN IN THE CITY OF NIŠ, SERBIA?
}

\author{
Aleksandra Stanković1, 2, Dragan Bogdanović3,4, Maja Nikolić1,2, Marija Anđelković Apostolović ${ }^{4,5}$ \\ ${ }^{1}$ Department of Hygiene, Medical Ecology, Medical Faculty, University of Niš, Niš, Serbia \\ ${ }^{2}$ Centre for Hygiene and Human Ecology, Public Health Institute Nišs, Niš, Serbia \\ ${ }^{3}$ Department for Biomedical Science, State University of Novi Pazar, Novi Pazar, Serbia \\ ${ }^{4}$ Centre for Informatics and Biostatistics in Health Care, Public Health Institute Niš, Niš, Serbia \\ ${ }^{5}$ Department for Informatics and Biostatistics, Medical Faculty, University of Nišs, Nišs, Serbia
}

\begin{abstract}
SUMMARY
Objective: Epidemiological research has shown that air pollution is associated with cardiovascular events, but little is known about short-term effects on blood pressure (BP) and heart rate (HR) in Serbian population. The present study assessed the short-term association between black smoke (BS) and sulphur dioxide $\left(\mathrm{SO}_{2}\right)$ levels in urban air and the daily values of blood pressure and heart rate in 98 healthy nonsmoking female volunteers.

Methods: Generalized regression model was fitted controlling for temperature, relative humidity, air pressure, season, and the day of the week.

Results: There was no association between short-term air pollution exposure and BP and HR, the exposure showed a tendency toward a decrease of diastolic BP and HR, but with no statistical significance.

Conclusion: The present findings did not support the conclusion that current levels of ambient $\mathrm{BS}$ and $\mathrm{SO}_{2}$ may have an effect on blood pressure and heart rate in women.
\end{abstract}

Key words: short-term exposure, black smoke, sulphur dioxide, blood pressure, heart rate

Address for correspondence: M. Anđelković Apostolović, Centre for Informatics and Biostatistics in Health Care, Public Health Institute Niš, Bulevar dr Zorana Đinđića 50, 18000 Niš, Serbia. E-mail: drmari84@gmail.com

https://doi.org/10.21101/cejph.a5104

\section{INTRODUCTION}

There is growing evidence that air pollution can adversely affect cardiorespiratory health. Previous research has indicated that exposure to air pollution is associated with increased cardiopulmonary hospital admission and mortality (1-3). It has also been suggested that susceptible groups may be more at risk for air pollution exposure, like the eldery $(4,5)$, and people with chronic cardiorespiratory diseases $(6,7)$.

The mechanism of air pollution effect on the cardiovascular system has not yet been fully understood, although there are few assumptions. These assumptions include the systemic and local inflammations (8), alterations in blood coagulability (9), and alteration of the autonomic nervous system (10). Blood pressure (BP) and heart rate (HR) can be used to assess changes in the autonomic control of the heart and vascular tone. Information on the association between exposure to pollutants in the atmosphere and blood pressure and heart rate has already been published (11-13).

In Serbia, air pollution is a big problem, mainly as result of an extremely low level of environmental consciousness of citizens. Basically, the causes of pollution are bad quality motor fuels, the use of old vehicles without a catalytic converter, and outdated technologies in the industrial and energy sectors.

A primary objective of this study was to further examine short-term effects of air pollution on cardiac autonomic function, measured by blood pressure and heart rate, in a panel study of healthy volunteers who live in the most polluted city area.

\section{MATERIALS AND METHODS}

\section{Study Area and Population}

This study was conducted in Niš. The city of Niš is situated in the Nišava valley in Serbia. The central city area is at $194 \mathrm{~m}$ above sea level. The city area covers 596.71 square kilometres with a population of 392,340 citizens. Sources of air pollution in the city include heating and traffic. Air pollution levels in winter are generally higher because of temperature inversion episodes. Study area of the city was carefully selected, based on the highest annual mean concentrations of sulphur dioxide $\left(\mathrm{SO}_{2}\right)$ and black smoke (BS) in the past 10 years. 
The study was approved by the Public Health Institute Ethics Committee, and participants signed written informed consent. Participants were informed about the aim, performance and expected results of the study. Data were collected from 1 October to 31 October in 2014.

A total of 98 healthy female volunteers, aged between 20 and 40 years, participated in the study. Eligibility criteria for selection of participants in this study included the same ethnicity, living beyond $10 \mathrm{~km}$ of the sampling monitoring station, living for more than 5 years on the same residential address, not being occupationally exposed to gas/dusts/fumes, and being non-smoker. Exclusion criteria included the use of medications and history of cardiovascular and pulmonary diseases. Volunteers visited the Healthcare Centre Niš at noon every day during the study. After obtaining written informed consent, a semi-structured questionnaire was used to collect baseline data by trained interviewers. The physical examination was synchronously performed by nurses.

\section{Study Design}

This was a longitudinal, panel study.

\section{Air Pollution and Weather}

Daily records of air pollution were obtained from the Institute for Public Health Niš. The monitoring station was located downtown (the most polluted area) and provided 24-hour averages of sulphur dioxide $\left(\mathrm{SO}_{2}\right)$ and black smoke (BS). The sampling protocol was carried out by trained personnel. BS $\left(\mu \mathrm{g} / \mathrm{m}^{3}\right)$ was measured by the refractometry method and $\mathrm{SO}_{2}\left(\mu \mathrm{g} / \mathrm{m}^{3}\right)$ by spectrophotometry. Analytical methods were specified by national guidelines.

Mean daily temperature, mean relative humidity and mean barometric pressure values were obtained from the Republic Meteorological Department.

\section{Questionnaire}

Questionnaires were conducted by trained interviewers. The general questionnaire included information on age, employment, education, passive smoking (ETS) at home, physical activity, alcohol consumption, and family history of cardiovascular diseases.

\section{Outcomes and Health Assessment}

Each subject performed the following measurements: height, body weight, BP and HR by trained nurses.

\section{Anthropometry}

Standing height and body weight were measured by standard procedure. Body mass index (BMI) was calculated as weight/ height squared (kilograms per meter squared).

\section{BP and HR Measurement}

At each clinical visit, a physician measured BP using a standard mercury sphygmomanometer after a five-minute rest. Systolic BP (SBP) and diastolic BP (DBP) were measured in each arm to the nearest $2 \mathrm{~mm} \mathrm{Hg}$ while the participant was seated. The means of the right and left arm measurements were used as the BP measurement of each participant for analytical purposes. Pulse palpation was measured for 60 seconds.

\section{Statistics}

Generalized regression model was applied to investigate air pollution effects on blood pressure and heart rate. This model used blood pressure and heart rate as the response variables, and daily mean values of pollutant concentrations, temperature, relative humidity, air pressure, season, and the day of the week as the independent variables. Basic regression model building was done for each dependent variable separately. Polynomial and natural cubic parametric functions were applied to explore the shape of the association between confounders and dependent variable. The relationship between the concentration of pollutants and dependent variables is considered linear. The model fitting was based on Akaike's Information Criterion. We assessed the effects of lagging exposure for 0, 1 and 2 days (lag 0, lag 1, lag 2 , respectively) as well as cumulative lag $0-5$. Lag 0 was defined as the 24-hour period from midnight of the day of the exposure, and lag 1 as the preceding 24-hour period, and so on. In cumulative lags (lag 0-5), we examined average concentrations on the day of the exposure and the previous days. Analyses were done using S-PLUS 2000 software.

\section{RESULTS}

Ninety-eight healthy nonsmoking female volunteers of mean age $37.7 \pm 9$ (range 20-40) years with normal cardiovascular function were recruited (Table 1). More than $50 \%$ of women reached a secondary educational level. Over fifteen percent of these individuals reported exposure to ETS at home. Use of alcohol was present in two women (2\%). Physical activity was practiced by nine women $(9.2 \%)$.

Table 1. Main characteristics of the study population $(N=98)$

\begin{tabular}{|l|c|}
\hline Characteristic & Mean \pm SD or $\mathbf{n}(\%)$ \\
\hline Age (years) & $37.7 \pm 9$ \\
\hline Employment, Yes & $29(29.6)$ \\
\hline Educational level \\
\hline Primary & $1(1.0)$ \\
\hline Secondary & $53(54.1)$ \\
\hline University or similar & $44(44.9)$ \\
\hline Passive smoking, Yes & $15(15.3)$ \\
\hline Drinking alcohol, Yes (g/day) & $2(2.0)$ \\
\hline Physical activity, Yes (hrs/week) & $9(9.2)$ \\
\hline Positive cardiovascular familiar anamnesis & $11(11.2)$ \\
\hline Systolic blood pressure (mm Hg) & $143.0 \pm 8.9$ \\
\hline Diastolic blood pressure (mm Hg) & $82.3 \pm 8.2$ \\
\hline Resting heart rate (beats/min) & $79.8 \pm 6.7$ \\
\hline Body mass index (kg/m²) & $23.6 \pm 2.87$ \\
\hline
\end{tabular}

$\mathrm{SD}$ - standard deviation 
Table 2 presents the summary of daily meteorological and pollution statistics. The daily mean level for BS was $40.38 \pm 18.44$ $\mu \mathrm{g} / \mathrm{m}^{3}$, minimum $5.0 \mu \mathrm{g} / \mathrm{m}^{3}$ and maximum $73 \mu \mathrm{g} / \mathrm{m}^{3}$. During the investigation period, concentrations of BS did show higher concentrations than allowed maximums according to the Serbian National Ambient Air Quality Standards $\left(50 \mu \mathrm{g} / \mathrm{m}^{3}\right)$ only in four days. Concentrations of $\mathrm{SO}_{2}$ had no significant variations. The daily mean data for temperature ranged from -1.0 to $13.2^{\circ} \mathrm{C}$ and the daily mean data for relative humidity ranged from 979.9 to $1,008.9 \%$. The daily mean data for air pressure ranged from 52.0 to 95.0 mbar.

$\mathrm{BS}$ and $\mathrm{SO}_{2}$ showed moderate correlation, as well as with air pressure (Table 3 ). The pollutants did not present positive correlation with temperature and relative humidity.

Table 4 and Figures 1-3 summarize the results of BS and $\mathrm{SO}_{2}$ influence on blood pressure and heart rate. There was no significant correlation between systolic blood pressure and levels of $\mathrm{BS}$ and $\mathrm{SO}_{2}$. An increase of $10 \mu \mathrm{g} / \mathrm{m}^{3}$ of BS was associated with estimated decrease in mean diastolic BP, but without statistical significance. $\mathrm{SO}_{2}$ increasing for $10 \mu \mathrm{g} / \mathrm{m}^{3}$ led to decreasing BP (except lag 0 ), but was not statistically significant. The magnitude of association for HR for lagged (lag 0, lag 1, lag 2 and lag 0-5) levels of both $\mathrm{BS}$ and $\mathrm{SO}_{2}$ were not statistically significant.

\section{DISCUSSION}

We identified no significant effects of short-term air pollution exposure on blood pressure and heart rate in healthy adults in this study. These effects were seen with certain pollutants (BS and $\mathrm{SO}_{2}$ ) and observed only in women, suggesting that sex may be an effect modifier.

BS exposure can lead to various changes in the human body. BS can provoke formation of reactive oxygen species in vivo, leading to inflammation and cellular damage (14). Inflammation is more present in elderly male population (15).

Changes in BP are caused by effect of the particles on increased baroreceptor reflex sensitivity (16). BS did not show a significant association with blood pressure and heart rate in our study. Surveys results are different, some studies have shown the impact of

Table 2. Summary of daily meteorological and pollution statistics

\begin{tabular}{|l|c|c|c|c|c|c|}
\hline Parameter & Mean \pm SD & Minimum & 25th percentile & 50th percentile & 75th percentile & Maximum \\
\hline Temperature $\left({ }^{\circ} \mathrm{C}\right)$ & $5.65 \pm 3.34$ & -1.0 & 4.5 & 6.0 & 7.7 & 13.2 \\
\hline Relative humidity $(\%)$ & $996.5 \pm 8.4$ & 979.9 & 990.2 & 999.0 & $1,003.0$ & $1,008.9$ \\
\hline Air pressure $(\mathrm{mbar})$ & $77.13 \pm 8.71$ & 52.0 & 73.3 & 77.0 & 82.0 & 95.0 \\
\hline $\mathrm{BS}\left(\mu \mathrm{g} / \mathrm{m}^{3}\right)$ & $40.38 \pm 18.44$ & 5.0 & 26.5 & 43.0 & 54.0 & 73.0 \\
\hline $\mathrm{SO}_{2}\left(\mu \mathrm{g} / \mathrm{m}^{3}\right)$ & $12.01 \pm 4.12$ & 2.6 & 9.2 & 12.0 & 13.9 & 22.1 \\
\hline
\end{tabular}

$\mathrm{SD}$ - standard deviation, $\mathrm{BS}$ - black smoke, $\mathrm{SO}_{2}$ - sulfur dioxide

Table 3. Pearson correlation coefficients among environmental variables

\begin{tabular}{|l|c|c|c|c|}
\hline Variable & Relative humidity & Air pressure & Temperature & $\mathbf{S O}_{2}$ \\
\hline $\mathrm{BS}$ & -0.192 & 0.470 & 0.272 & 0.528 \\
\hline $\mathrm{SO}_{2}$ & -0.242 & 0.514 & 0.043 & \\
\hline Temperature & -0.595 & -0.466 & & \\
\hline Air pressure & 0.344 & & & \\
\hline
\end{tabular}

$\mathrm{BS}$ - black smoke, $\mathrm{SO}_{2}$ - sulfur dioxide

Table 4. $95 \% \mathrm{Cl} / 10 \mu \mathrm{g} / \mathrm{m}^{3}$ increase in concentration of $\mathrm{BS}$ and $\mathrm{SO}_{2}$ for daily values of systolic blood pressure, diastolic blood pressure and heart rate

\begin{tabular}{|c|c|c|c|c|c|c|c|c|c|c|c|c|}
\hline \multirow{3}{*}{ Pollutant } & \multicolumn{4}{|c|}{ Systolic blood pressure } & \multicolumn{4}{|c|}{ Diastolic blood pressure } & \multicolumn{4}{|c|}{ Resting hearth rate } \\
\hline & \multirow{2}{*}{ Lag } & \multirow{2}{*}{$\beta$} & \multicolumn{2}{|c|}{$95 \% \mathrm{Cl}$} & \multirow{2}{*}{ Lag } & \multirow{2}{*}{$\beta$} & \multicolumn{2}{|c|}{$95 \% \mathrm{Cl}$} & \multirow{2}{*}{ Lag } & \multirow{2}{*}{$\beta$} & \multicolumn{2}{|c|}{$95 \% \mathrm{Cl}$} \\
\hline & & & Lower & Upper & & & Lower & Upper & & & Lower & Upper \\
\hline \multirow{4}{*}{ BS } & 0 & -0.62 & -1.39 & 0.16 & 0 & -0.18 & -0.55 & 0.20 & 0 & -0.45 & -1.14 & 0.24 \\
\hline & 1 & 0.22 & -0.44 & 0.89 & 1 & -0.14 & -0.53 & 0.26 & 1 & -0.19 & -0.62 & 0.25 \\
\hline & 2 & 0.09 & -0.50 & 0.69 & 2 & -0.01 & -0.39 & 0.38 & 2 & -0.55 & -1.17 & 0.08 \\
\hline & $0-5$ & -0.35 & -1.34 & 0.64 & $0-5$ & -0.59 & -1.19 & 0.00 & $0-5$ & -0.25 & -1.01 & 0.52 \\
\hline \multirow{4}{*}{$\mathrm{SO}_{2}$} & 0 & 0.81 & -1.39 & 3.01 & 0 & 0.43 & -1.20 & 2.05 & 0 & -0.90 & -2.57 & 0.78 \\
\hline & 1 & -0.40 & -1.72 & 0.92 & 1 & -0.15 & -0.85 & 0.56 & 1 & -0.11 & -1.02 & 0.79 \\
\hline & 2 & -1.84 & -10.54 & 6.87 & 2 & -1.32 & -5.57 & 2.93 & 2 & -0.59 & -5.61 & 4.43 \\
\hline & $0-5$ & 0.16 & -6.99 & 7.32 & $0-5$ & -1.55 & -5.81 & 2.71 & $0-5$ & -1.20 & -6.33 & 3.93 \\
\hline
\end{tabular}

$\mathrm{BS}$ - black smoke, $\mathrm{SO}_{2}$ - sulfur dioxide, $\beta$ - Beta regression coefficient, $\mathrm{Cl}$ - confidence interval 


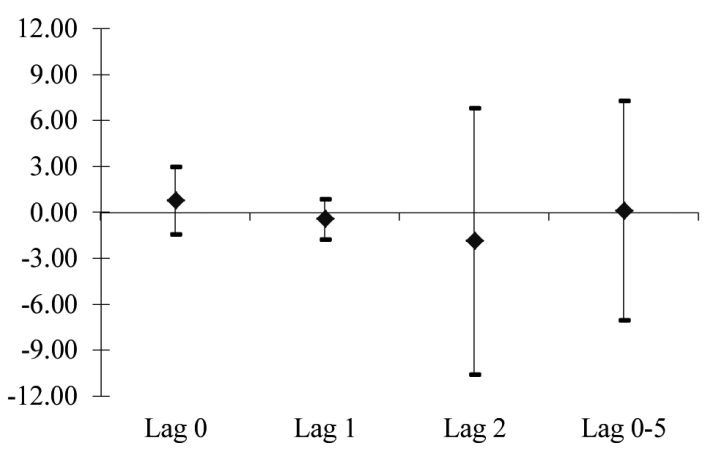

(A)

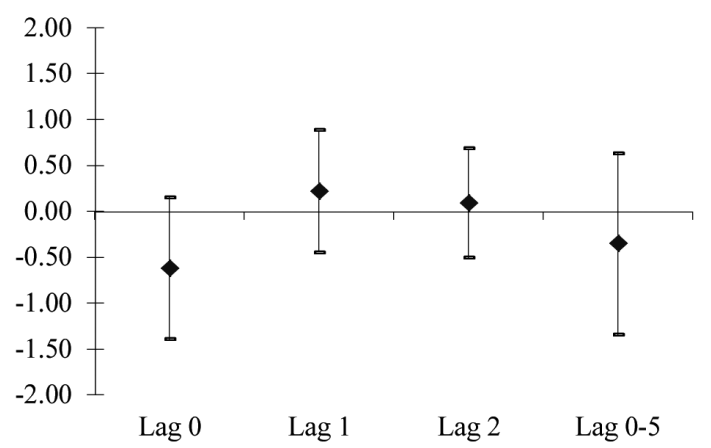

(B)

Fig. 1. (A) Association between $\mathrm{SO}_{2}$ and $\mathrm{SBP}$, (B) Association between BS and SBP.

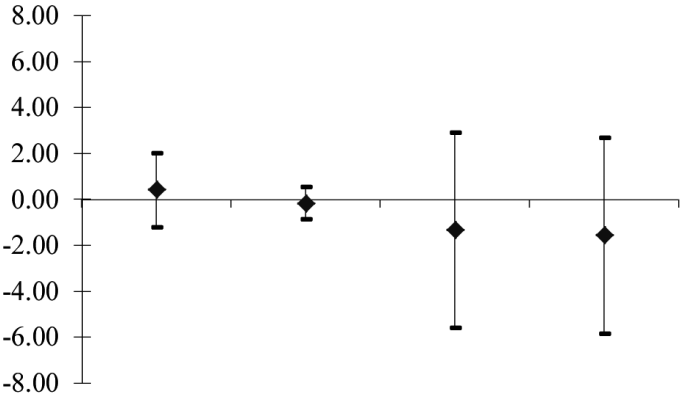

$\operatorname{Lag} 0 \quad$ Lag $1 \quad$ Lag $2 \quad$ Lag $0-5$

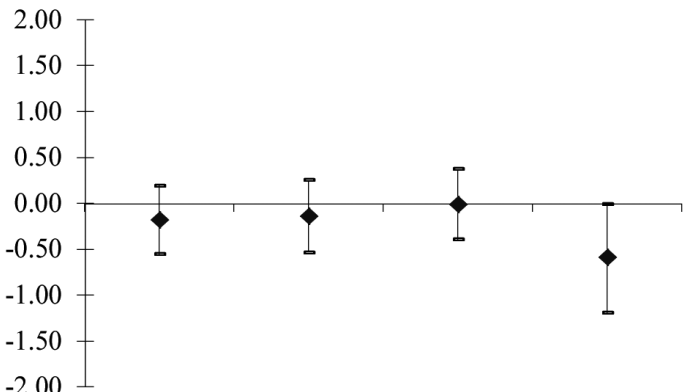

$\operatorname{Lag} 0 \quad$ Lag $1 \quad \operatorname{Lag} 2 \quad$ Lag $0-5$
(A)

Fig. 2. (A) Association between $\mathrm{SO}_{2}$ and $D B P$, (B) Association between $B S$ and DBP.

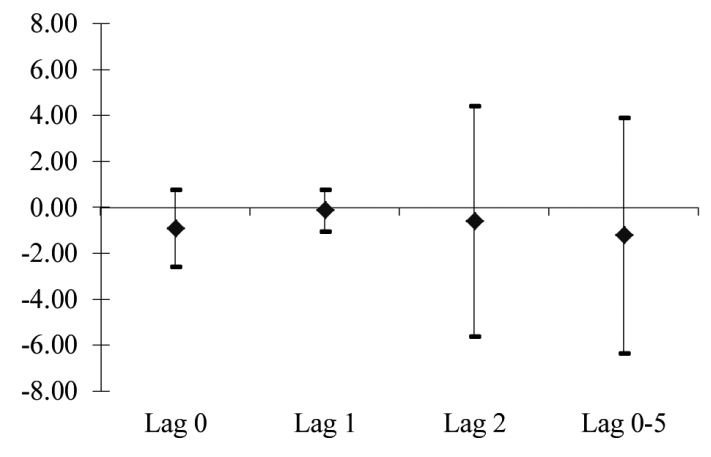

(A)

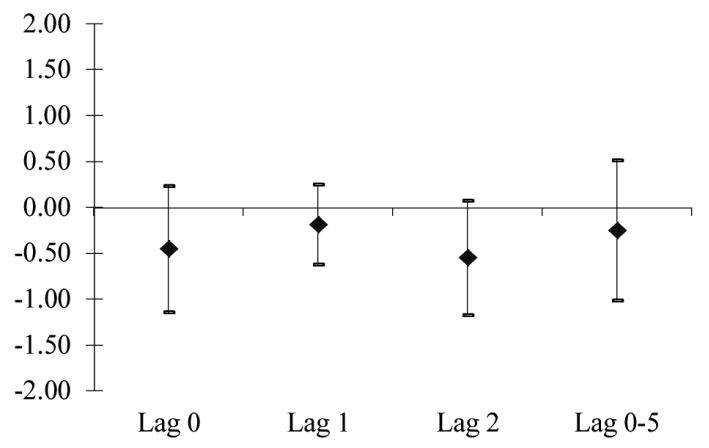

(B)

Fig. 3. (A) Association between $\mathrm{SO}_{2}$ and $\mathrm{HR}$, (B) Association between $B S$ and $H R$.

short-term air pollution exposure on BP, but other studies have not. In the study of Brook et al. (17) community levels were not associated with cardiovascular outcomes, but $10 \mu \mathrm{g} / \mathrm{m}^{3}$ increase in total personal-level exposure was associated with systolic blood pressure elevation $(+1.41 \mathrm{~mm} \mathrm{Hg}$, lag day $1, \mathrm{p}<0.001)$. In other study interquartile increase of $\mathrm{PM}_{10}$ was associated with lag 0 , mainly on systolic blood pressure (18). Increased particulate matter with aerodynamic diameters $<10$ micro was associated with elevated systolic blood pressure (interquartile range, $34 \mu \mathrm{g} / \mathrm{m}$, for $0.47 \mathrm{~mm} \mathrm{Hg}$; 95\% CI: -0.09 to 1.02 ), triglyceride, apolipoprotein $\mathrm{B}$, haemoglobin $\mathrm{A} 1 \mathrm{C}$, and reduced high-density lipoprotein cholesterol (19). Louwies et al. suggested that the changes in a person's blood pressure as a result of subchronic BS exposure operate independently of the retinal microcirculation (20).

Also, Liu et al. found that increases in black carbon and $\mathrm{PM}_{2.5}$ were associated with increases in blood pressure and heart rate in nonsmoking seniors (21). $\mathrm{PM}_{10}$ was associated with elevated systolic blood pressure (interquartile range, $34 \mu \mathrm{g} / \mathrm{m}$, for 0.47 mm Hg; 95\% CI: -0.09 to 1.02 ).

Heart rate is not a stable value and it increases or decreases in response to the body need to maintain basal metabolic rate between requirement and delivery of oxygen and nutrients. Men 
had more pronounced sympathetic influence than women in cardiac regulation and heart rate variability (HRV) declined linearly with age (22). As well as in BP, some studies have demonstrated a correlation between short term exposure to air pollution and heart rate, while others have found no association between the two.

Regular aerobic training usually results in significant reductions in heart rates both at rest and during submaximal exercise (23). Our healthy volunteers were reported to exercise regular physical activity, which may be just one of the possible reasons why short-term exposure to air pollution had no effect on the increase in heart rate.

Short-term exposure to $\mathrm{PM}_{10}$ reduces pulse pressure and age, sex, and hypertensive status may modify the effects of $\mathrm{PM}_{10}$ on pulse pressure (24). Adar et al. reported that BS are negatively associated with heart rate variability in the elderly (25).

Luz and Pope found that short-term differences in air pollution, specifically $\mathrm{PM}_{2.5}$ concentration, did not affect ventricular repolarization (26). In contrast to this study, other studies (27, 28) confirmed marked changes in traffic-related $\mathrm{PM}_{2.5}$ exposure which were associated with altered cardiac autonomic function in young healthy adults. Changes in air pollution indices may lead to the occurrence of non-sustained supraventricular tachycardia, a slight reduction in maximum heart rate (29). Chan et al. reported that HRV was not associated with $\mathrm{PM}_{10}, \mathrm{CO}, \mathrm{SO}_{2}$, or $\mathrm{O}_{3}(30)$.

Our study has some limitations. First, we used environmental monitoring data for the exposure of each individual to air pollution. Therefore, measurement errors resulting from differences between actual exposure and ambient levels cannot be avoided. However, this error is more likely to cause a bias towards the null and underestimate the pollution effects. Second, there is also the possibility of error in the blood pressure measurement because we used the data measured once from both arms by standard mercury sphygmomanometer. Data on large BP variability that occurs throughout the day would be more valid if we had used holter monitors, but it would be too costly and unfeasible within the public health system.

Despite these limitations, this study has several strengths. We avoided the self-measured BP since BP was measured by trained nurses. Considering the fact that the participants in our study were females, on the basis of our results we have proved that females are not necessarily more vulnerable to ambient air pollutants. Due to equipment shortage for measuring $\mathrm{PM}_{10}$ and $\mathrm{PM}_{2.5}$ we used BS measurement data. However, BS could serve as a useful marker in epidemiological studies and BS level are much more directly influenced by local traffic sources than other pollutants.

\section{CONCLUSION}

Conclusions of our study indicate that air pollution is not associated with blood pressure and heart rate in women. These results provide evidence that current levels of air pollution in Niš were not associated with adverse health outcomes. In the view of low ambient concentration, monitoring of other pollutants, such as nitrogen dioxide and ozone, has been confined to only one station in Niš in recent years. Consequently, our obtained results are a baseline for further analytic epidemiological research on the association between exposure to other pollutants and blood pressure and heart rate.

\section{Acknowledgements}

This study was supported by the Ministry of Science and Technological Development of the Republic of Serbia (Project no. 42008 and Project no. 43014).

\section{Conflict of Interests}

None declared

\section{REFERENCES}

1. Almeida SM, Silva AV, Sarmento S. Effects of exposure to particles and ozone on hospital admissions for cardiorespiratory diseases in SetúBal, Portugal. J Toxicol Environ Health A. 2014; 77(14-16):837-48.

2. Zhou M, He G, Fan M, Wang Z, Liu Y, Ma J, et al. Smog episodes, fine particulate pollution and mortality in China. Environ Res. 2014;136:396404.

3. Milojevic A, Wilkinson P, Armstrong B, Bhaskaran K, Smeeth L, Hajat $\mathrm{S}$. Short-term effects of air pollution on a range of cardiovascular events in England and Wales: case-crossover analysis of the MINAP database, hospital admissions and mortality. Heart. 2014; 100(14):1093-8.

4. Wang MZ, Zheng S, He SL, Li B, Teng HJ, Wang SG, et al. The association between diurnal temperature range and emergency room admissions for cardiovascular, respiratory, digestive and genitourinary disease among the elderly: a time series study. Sci Total Environ. 2013;456-457:370-5.

5. Rodopoulou S, Chalbot MC, Samoli E, Dubois DW, San Filippo BD, Kavouras IG. Air pollution and hospital emergency room and admissions for cardiovascular and respiratory diseases in Doña Ana County, New Mexico. Environ Res. 2014;129:39-46.

6. Lin CM, Kuo HW. Sex-age differences in association with particulate matter and emergency admissions for cardiovascular diseases: a hospitalbased study in Taiwan. Public Health. 2013;127(9):828-33.

7. Dehghani M, Anushiravani A, Hashemi H, Shamsedini N. Survey on air pollution and cardiopulmonary mortality in shiraz from 2011 to 2012: an analytical-descriptive study. Int J Prev Med. 2014;5(6):734-40.

8. Routledge HC, Ayres JG, Townend JN. Why cardiologists should be interested in air pollution? Heart. 2003;89(12):1383-8.

9. Riediker M, Devlin RB, Griggs TR, Herbst MC, Bromberg PA, Williams RW, et al. Cardiovascular effects in patrol officers are associated with fine particulate matter from brake wear and engine emissions. Part Fibre Toxicol. 2004;1(1):2. doi: doi.org/10.1186/1743-8977-1-2.

10. Peters A, Froclich M, Doring A, Immervoll T, Wichmann HE, Hutchinson WL, et al. Particulate air pollution is associated with an acute phase response in men. Eur Heart J. 2001; 22(14):1198-204.

11. Liang R, Zhang B, Zhao X, Ruan Y, Lian H, Fan Z. Effect of exposure to PM2.5 on blood pressure: a systematic review and meta-analysis. J Hypertens. 2014;32(11):2130-40.

12. Riediker M, Cascio WE, Griggs TR, Herbst MC, Bromberg PA, Neas $\mathrm{L}$, et al. Particulate matter exposure in cars is associated with cardiovascular effects in healthy young men. Am J Respir Crit Care Med. 2004;169(8):934-40.

13. Pope CA III, Hansen ML, Long RW, Nielsen KR, Eatough NL, Wilson WE, et al. Ambient particulate air pollution, heart rate variability, and blood markers of inflammation. A panel of eldery subjects. Environ Health Perspect. 2004;112(3):339-45.

14. Shiraiwa M, Selzle K, Pöschl U. Hazardous components and health effects of atmospheric aerosol particles: reactive oxygen species, soot, polycyclic aromatic compounds and allergenic proteins. Free Radic Res. 2012;46(8):927-39.

15. Fang SC, Mehta AJ, Alexeeff SE, Gryparis A, Coull B, Vokonas P, et al. Residential black carbon exposure and circulating markers of systemic inflammation in elderly males: the normative aging study. Environ Health Perspect. 2012;120(5):674-80.

16. Bartoli CR, Wellenius GA, Diaz EA, Lawrence J, Coull BA, Akiyama I, et al Mechanisms of inhaled fine particulate air pollution-induced arterial blood pressure changes. Environ Health Perspect. 2009;117(3):361-6.

17. Brook RD, Bard RL, Burnett RT, Shin HH, Vette A, Croghan C, et al. Differences in blood pressure and vascular responses associated with ambient fine particulate matter exposures measured at the personal versus community level. Occup Environ Med. 2011;68(3): 224-30.

18. Sérgio Chiarelli P, Amador Pereira LA, Nascimento Saldiva PH, Ferreira Filho C, Bueno Garcia ML, Ferreira Braga AL, et al. The association 
between air pollution and blood pressure in traffic controllers in Santo André, São Paulo, Brazil. Environ Res. 2011;111(5):650-5.

19. Chuang KJ, Yan YH, Cheng TJ. Effect of air pollution on blood pressure, blood lipids, and blood sugar: a population-based approach. J Occup Environ Med. 2010;52(3):258-62.

20. Louwies T, Nawrot T, Cox B, Dons E, Penders J, Provost E, et al. Blood pressure changes in association with black carbon exposure in a panel of healthy adults are independent of retinal microcirculation. Environ Int. 2014;15;75:81-6.

21. Liu L, Ruddy T, Dalipaj M, Poon R, Szyszkowicz M, You H, et al. Effects of indoor, outdoor, and personal exposure to particulate air pollution on cardiovascular physiology and systemic mediators in seniors. J Occup Environ. 2009;51(9):1088-98.

22. Park SB, Lee BC, Jeong KS. Standardized tests of heart rate variability for autonomic function tests in healthy Koreans. Int J Neurosci. 2007;117(12):707-17.

23. Hottenrott K, Hoos O, Esperer HD. Heart rate variability and physical exercise: current status. Herz. 2006;31(6):544-52. (In German.)

24. Chen SY, Su TC, Lin YL, Chan CC. Short-term effects of air pollution on pulse pressure among nonsmoking adults. Epidemiology. 2012;23(2):3418.

25. Adar SD, Gold DR, Coull BA, Schwartz J, Stone PH, Suh H. Focused exposures to airborne traffic particles and heart rate variability in the elderly. Epidemiology. 2007;18(1):95-103.
26. Lux RL, Pope CA 3rd. Air pollution effects on ventricular repolarization. Res Rep Health Eff Inst. 2009;(141):3-20.

27. Wu S, Deng F, Niu J, Huang Q, Liu Y, Guo X. Association of heart rate variability in taxi drivers with marked changes in particulate air pollution in Beijing in 2008. Environ Health Perspect. 2010;118(1):87-91.

28. Wu S, Deng F, Niu J, Huang Q, Liu Y, Guo X. The relationship between traffic-related air pollutants and cardiac autonomic function in a panel of healthy adults: a further analysis with existing data. Inhal Toxicol. 2011;23(5):289-303.

29. Davoodi G, Sharif AY, Kazemisaeid A, Sadeghian S, Farahani AV, Sheikhvatan M, et al. Comparison of heart rate variability and cardiac arrhythmias in polluted and clean air episodes in healthy individuals. Environ Health Prev Med. 2010;15(4):217-21.

30. Chan CC, Chuang KJ, Su TC, Lin LY. Association between nitrogen dioxide and heart rate variability in a susceptible population. Eur J Cardiovasc Prev Rehabil. 2005;12(6):580-6.

Received March 14, 2017 Accepted in revised form April 15, 2018 